\title{
The chemical composition of a mixed bacteria population from the rumen of sheep fed different diets
}

\author{
J Kowalczyk, E Kwiatkowska \\ The Kielanowski Institute of Animal Physiology and Nutrition, Polish Academy of Sciences, \\ 05-110 Jabonna, Poland
}

\begin{abstract}
Estimation of bacterial protein in the rumen is based on indirect measurement of DAPA or RNA contents in the rumen bacteria. However, the chemical composition and DAPA or RNA levels in different strains of bacteria can differ and this can influence the results. The relative proportions of bacteria strains in the rumen depend on the diet composition and nutrient levels.
\end{abstract}

The aim of the experiment was to examine the chemical composition of a mixed population of bacteria in the rumen of sheep fed protein from different sources and of differing degradability.

The experiment was carried out with four groups of eight 5-month-old wethers of $40 \mathrm{~kg}$ body weight with cannulae into the rumen. The animals were fed for 3 months dried sugar beet pulp supplemented with untreated casein (CU) or rapeseed oilmeal (RU) or formaldehydetreated casein (CF) or formaldehyde treated rapeseed oilmeal (RF), respectively. The rations contained $20 \%$ crude fibre and $17 \%$ crude protein in DM ; about $50 \%$ of this protein was from casein or rapeseed oilmeal. The degradability constants of untreated or treated casein were : $a=98.5$ and $17.5 \%$ and $b=0$ and $82.2 \%$; for rapeseed oilmeal $\mathrm{a}=26.2$ and $9.5 \%$ and $b=67.5$ and $86.4 \%$, respectively. At the end of the feeding trial the rumen content was sampled and the bacterial mass was separated for analysis.

The relative proportions of rumen bacteria according to their shape were similar in groups $\mathrm{CU}$ and $\mathrm{RU}$ but those animals fed treated protein had increased numbers of small coliforms and lower numbers of large and small cocci.

Total-N, protein, RNA, DNA and DAPA contents in the bacterial mass did not differ among the groups. The carbohydrate content in groups CF and RF was lower than in groups $\mathrm{CU}$ and RU. The proportions of individual amino acids in bacterial protein were similar for all groups.

The source of protein did not affect the chemical composition of the bacterial mass but formaldehyde-treated protein did lead to a decreased carbohydrate content.

\begin{tabular}{lcccc}
\hline Component (\% of DM) & CU & CF & RU & RF \\
\hline Total nitrogen & 9.85 & 9.78 & 9.73 & 9.90 \\
Protein & 61.17 & 61.06 & 60.15 & 59.37 \\
RNA & 11.88 & 11.69 & 11.78 & 10.89 \\
DNA & 2.05 & 2.96 & 3.10 & 3.49 \\
DAPA & 0.45 & 0.45 & 0.44 & 0.44 \\
DAPA in protein & 0.98 & 0.98 & 0.98 & 0.91 \\
Carbohydrates & $18.73^{\mathrm{a}}$ & $12.53^{\mathrm{b}}$ & $18.25 \mathrm{a}$ & $11.09 \mathrm{~b}$ \\
Lipids & 13.01 & 13.84 & 13.39 & 14.50 \\
\hline
\end{tabular}

